Lauren Anne Buehler, MD, MPH

Endocrinologist, Conway Medical Center,

Conway, SC
Dawn Noe, RDN, LD, CDCES

Registered Dietitian Nutritionist, Dawn Noe

Nutrition and Consulting, Cleveland, $\mathrm{OH}$
Shannon Knapp, BSN, RN, CDCES

Manager of Diabetes Care and Education,

Endocrinology and Metabolism Institute,

Cleveland Clinic, Cleveland, $\mathrm{OH}$
Diana Isaacs, Pharm D, CDCES Pharmacy Clinical Specialist, Continuous Glucose Monitor and Remote Monitoring Program Coordinator, Endocrinology and Metabolism Institute, Cleveland Clinic, Cleveland, $\mathrm{OH}$
Kevin M. Pantalone, DO, ECNU, FACE

Staff Endocrinologist, Director of Diabetes Initiatives,

Endocrinology and Metabolism Institute, Cleveland

Clinic, Cleveland, $\mathrm{OH}$

\title{
Ketogenic diets in the management of type 1 diabetes: Safe or safety concern?
}

\section{ABSTRACT}

The jury is still out on whether a low-carbohydrate, ketosis-inducing diet is an effective and safe adjunctive therapy to insulin in type 1 diabetes. The limited published literature reports an association with weight loss and improved glycemic control and may, over the longterm, lead to reduced macrovascular and microvascular harm. However, the attendant increased risk of dyslipidemia, diabetic ketoacidosis, and hypoglycemia warrant caution, close monitoring of patients who embark on the diet, and further research.

\section{KEY POINTS}

Ketogenic diets are high in fat, moderate in protein, and low in carbohydrate; they should be well formulated for maximal nutritional benefit and well-being.

Ketogenic diets have been reported to improve hemoglobin A1c and glycemic variability in patients with type 1 diabetes and may improve biochemical and physical markers of cardiovascular risk.

Key safety concerns include the risk of dyslipidemia, diabetic ketoacidosis, and hypoglycemia.

Insulin therapy usually requires adjustment when starting a ketogenic diet, and patients should be closely monitored.

Sodium-glucose cotransporter 2 inhibitors should be discontinued when following a ketosis-inducing diet, but metformin is considered safe. Glucagon-like peptide 1 receptor agonists can be continued with close monitoring.
3 I-YEAR-OLD MAN WITH A I 4-YEAR HISTORY $A$ of type 1 diabetes presented for routine follow-up. He had been on hybrid closedloop insulin pump therapy for 6 months. Before using this system, he used multiple daily injections of insulin, with hemoglobin A1c (HbA1c) levels ranging from $7.5 \%$ to $9.0 \%$ (target range $<7 \%$ ). Glycemic control improved on insulin pump therapy but was still subpar (HbA1c 7.7\%) and highly variable. He self-initiated a very-low-carbohydrate, ketosisinducing diet ( $<30 \mathrm{~g}$ of carbohydrates per day), self-adjusted his insulin pump settings, and subsequently reported that his glucose control improved with minimal hypoglycemia.

His $\mathrm{HbA1c}$ was $5.7 \%$, and he weighed 18 lbs less than at his previous visit (pre-diet body mass index [BMI] $30.4 \mathrm{~kg} / \mathrm{m}^{2}$ ). Glucose levels were reported as within the desired range (3.9-10.0 $\mathrm{mmol} / \mathrm{L}[70-180 \mathrm{mg} / \mathrm{dL}]$ ) $97 \%$ of the time, with very few boluses of insulin required. The patient inquired if this dieting program was safe in patients with type 1 diabetes.

\section{KETOGENIC DIET AND DIABETES TYPE}

Ketogenic diets have risen in popularity in recent years as a strategy for weight loss and treatment of a variety of diseases. For patients with type 2 diabetes mellitus, the diet can lead to clinical improvement, including better glycemic control, lower cholesterol, and weight reduction. ${ }^{1-3}$

The diet is also becoming popular among patients with type 1 diabetes, but its clinical impact remains unclear, as much of the literature consists of retrospective case reports and series. The subject has not been well investigated, likely because of concern about induc- 
ing ketoacidosis and hypoglycemia in patients already at high risk for these complications.

This article reviews potential risks and benefits of a ketogenic diet for managing type 1 diabetes based on available evidence.

\section{KETOGENIC DIET PARAMETERS}

Ketogenic diets are generally high in fat $(60 \%-85 \%)$, moderate in protein $(15 \%-30 \%)$, and low in carbohydrates $(5 \%-10 \%) .{ }^{4}$ This leads to the body using fat as its principal energy source.

Total caloric needs and preferred macronutrient distribution can be calculated using one of a variety of formulas (eg, Mifflin-St. Jeor). ${ }^{5}$ Unfortunately, the literature of ketogenic and very-low carbohydrate diets varies in defining diet composition. Feinman et $\mathrm{al}^{6}$ define a verylow carbohydrate ketogenic diet as containing 20 to $50 \mathrm{~g}$ of carbohydrate in a 2,000 calorie diet, or less than $10 \%$ of total energy intake.

Common misconceptions about ketogenic diets are that followers can consume few vegetables and must eat excessive amounts of meat. But a well-formulated diet can incorporate a variety of protein-containing foods, including fish, cheese, and Greek-style yogurt. The diet may also include 4 or 5 servings of vegetables daily, which contain about 20 to 30 grams of carbohydrate in total; hence, the low amount of allowable carbohydrate may be obtained entirely from vegetables. Fat calories can also come from plants and fish that are on the Mediterranean diet, such as olives, olive oil, nuts, seeds, avocado, tuna, and salmon.

A long-term ketogenic diet should be designed to meet all nutritional needs. Using a hypothetical case study design, Zinn et $\mathrm{al}^{7}$ demonstrated that a low-carbohydrate, highfat diet ( $10 \%$ of calories from carbohydrate) could be formulated to be micronutrient replete. Further, nutrition counseling and attention to hydration can ensure that appropriate amounts of electrolytes such as sodium, potassium, and magnesium are achieved.

\section{BIOCHEMISTRY OF KETOSIS}

Under normal physiologic circumstances, glucose is the main substrate for glycolysis, resulting in the production of adenosine triphosphate (ATP), the body's main energy source.
Under circumstances of starvation or dietary carbohydrate restriction, the body breaks down glycogen (ie, the storage form of glucose) in the liver to provide the body with glucose.

In a prolonged fasting or carbohydrate-restricted state ( $>48-72$ hours), liver glycogen stores become depleted. Without glucose as a substrate for ATP production, the liver breaks down triglycerides to make ketone bodies that travel to target tissues (eg, brain, muscles) and ultimately generate ATP. ${ }^{8,9}$ This process of ketogenesis is regulated by insulin; low carbohydrate intake leads to low insulin levels, promoting ketosis. ${ }^{10}$

\section{MONITORING KETONES}

For patients with type 1 diabetes, monitoring ketones is important to identify and prevent diabetic ketoacidosis (DKA). Three types of ketone bodies, resulting from the liver metabolizing fatty acids, are measured in different ways, each with advantages and disadvantages: acetone, acetoacetic acid, and beta-hydroxybutyrate. ${ }^{11}$

Acetone is measured with a breath test. Breath analyzers are painless, convenient, and noninvasive. Although they can cost more than blood ketone meters, breath analyzers typically do not have recurring costs. However, research on the accuracy of breath analyzers is limited, and several available devices are not approved by the US Food and Drug Administration.

Acetoacetic acid is measured in urine. Urine ketone tests are painless, inexpensive, and noninvasive. However, they are not ideal for early detection of DKA, as results provide an average of urine ketone concentration since the last void rather than reflect current ketone levels.

Beta-hydroxybutyrate is measured in capillary blood. Blood ketone measurements provide timely identification of DKA, as they measure the current plasma concentration of beta-hydroxybutyrate, the ketone body that appears earliest in DKA. They also are more sensitive and specific than urine tests. However, blood tests are invasive, and the cost includes the initial purchase of a meter in addition to the recurring expense for disposable test strips and lancets. 


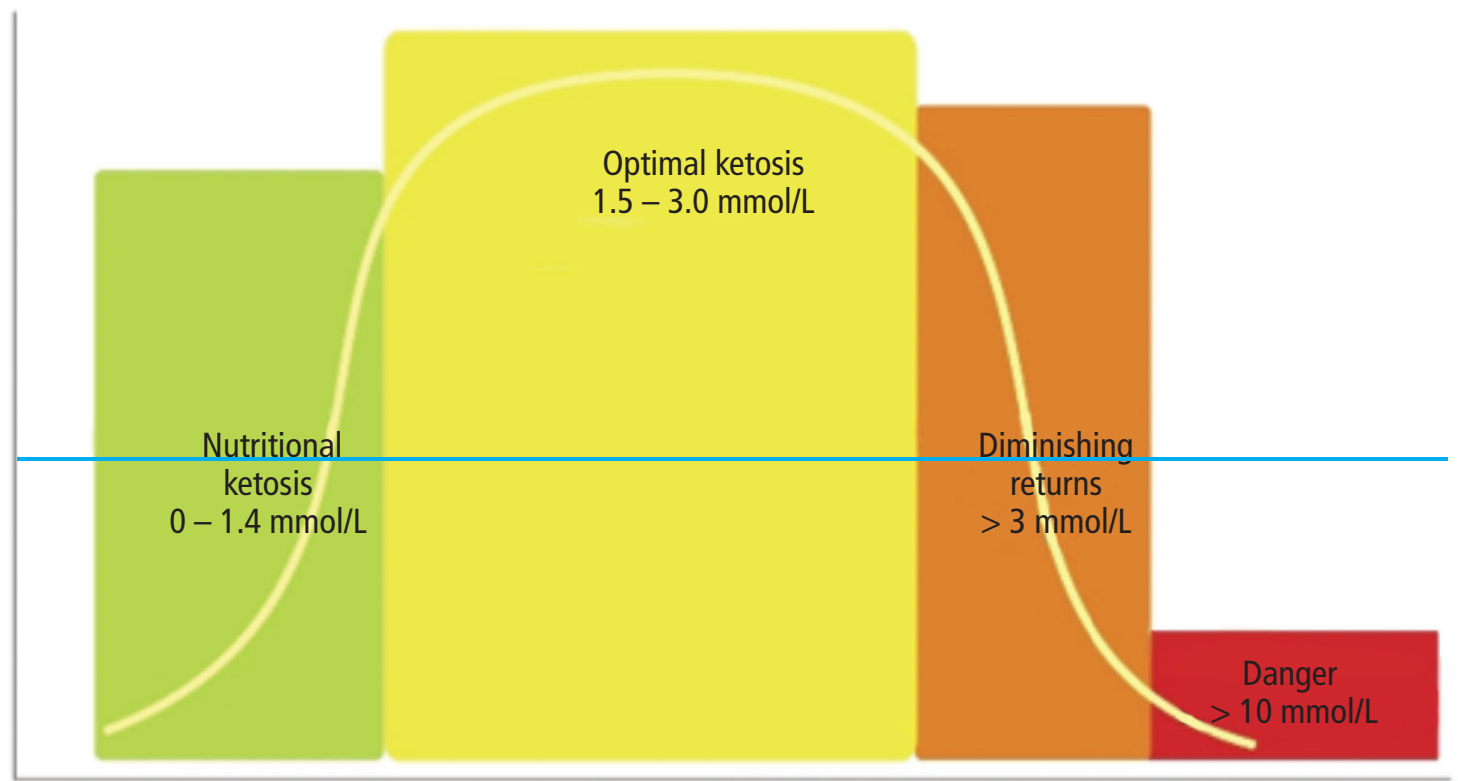

Serum ketone level

Figure 1. Safety ranges of serum ketone levels.

Based on data from reference 12 .

\section{DKA OR DESIRED KETOSIS?}

Differentiating DKA from desired nutritional ketosis for a patient following a ketogenic diet poses a challenge when interpreting monitored test results. According to Volek and Phinney, ${ }^{12}$ blood ketone levels ranging from 0.5 to $3.0 \mathrm{mmol} / \mathrm{L}$ are expected in nutritional ketosis, with the upper end $(1.5-3.0 \mathrm{mmol} / \mathrm{L})$ being optimal (Figure 1). ${ }^{12}$ Although such levels are not high enough to indicate DKA, they can be a warning sign. As such, the clinical picture should be considered. Patients should be educated regarding symptoms of DKA, including nausea, vomiting, and difficulty breathing.

Diligent and more frequent blood glucose monitoring should be a mainstay in patients with diabetes on a ketogenic diet. Although euglycemic DKA is possible while following a ketogenic diet, blood glucose levels above 250 $\mathrm{mg} / \mathrm{dL}$ may be seen and are a sign of potential DKA.

Glucose monitoring can also be helpful for preventing hypoglycemia, a potential consequence of reduced carbohydrate intake. Clinical studies indicate that a continuous glucose monitor (CGM) can be a useful tool in reducing hypoglycemia. ${ }^{13,14}$

\section{ADJUSTING DIABETES THERAPIES}

Little has been published on how to adjust medications in people with type 1 diabetes who follow a ketogenic diet.

\section{Insulin requirements change}

Ranjan et $\mathrm{a}^{15}$ conducted a small, randomized crossover study of a high-carbohydrate vs lowcarbohydrate diet in patients with type 1 diabetes. All patients used an insulin pump with a CGM. Insulin pump settings were optimized in a 2- to 3-week period before the diet. The diets resulted in similar basal insulin requirements, but the total bolus dosage was lower in the low-carbohydrate diet group (defined as $\leq 50 \mathrm{~g}$ carbohydrates per day), with the total daily insulin dose reduced by $44.3 \%$. This is similar to that observed in clinical trials in patients with type 2 diabetes starting a low-carbohydrate diet, in which insulin dosages are typically decreased by $50 \% .^{1,16,17}$ A key difference is that people with type 2 diabetes on a low-carbohydrate diet can usually completely stop bolus doses in addition to reducing basal insulin. ${ }^{18}$

In clinical practice, it is not uncommon to escalate basal insulin rather than add or increase bolus doses, thus allowing the long-acting insulin to cover some or all of a patient's 
post-meal insulin needs. In such cases, excessive basal coverage can increase the risk of hypoglycemia when a patient reduces mealtime carbohydrate intake when starting a ketogenic diet. Furthermore, many people with type 1 diabetes have an elevated BMI, and insulin resistance is expected to improve and insulin requirements decrease as weight is lost on a ketogenic diet.

\section{How to adjust insulin}

Insulin dosages usually need to be reduced after starting a ketogenic diet; in type 1 diabetes, this usually entails decreasing the amount of insulin received per gram of carbohydrate. The following strategy can be used:

- If a patient's $\mathrm{HbA1c}$ is near target, the daily dosage of basal insulin may need to be decreased by $10 \%$ to $20 \%$

- If the HbA1c is elevated, no adjustments may be required

- It is often safest to adjust insulin with the aim of reducing the risk of hypoglycemia; the patient can be instructed to take additional correction doses of short-acting insulin to address hyperglycemia

- Insulin dosages often need to be adjusted weekly in the initial stages as weight loss and adherence to the ketogenic diet will impact the necessary insulin adjustments, and these factors are highly individual.

\section{Other diabetes medications}

Usually with the aim of weight loss, many patients with type 1 diabetes also take medications off-label that are approved by the US Food and Drug Administration for type 2 diabetes, including metformin, sodiumglucose cotransporter 2 (SGLT-2) inhibitors, and glucagon-like peptide 1 (GLP-1) receptor agonists.

SGLT-2 inhibitors are associated with an increased risk of euglycemic DKA, particularly in type 1 diabetes. This may occur through multiple mechanisms, including reduction in insulin-mediated suppression of lipolysis and ketogenesis, volume contraction, promotion of glucagon secretion, and decrease in renal clearance of ketone bodies. ${ }^{19}$ Accordingly, SGLT-2 inhibitors should be stopped before starting a ketogenic diet owing to the risk of DKA that often presents as euglycemic, making it difficult to recognize. ${ }^{20}$
GLP-1 receptor agonists, when used in type 1 diabetes, may increase the risk of hypoglycemia and DKA. ${ }^{21,22}$ They can be continued with close monitoring in patients following a ketogenic diet, although some providers prefer to stop them.

Metformin is generally considered safe to continue. ${ }^{23}$

\section{BLOOD GLUCOSE CONTROL: A BALANCING ACT}

Optimizing glycemic control in type 1 diabetes can be extremely challenging but is essential to prevent life-threatening, short-term complications such as DKA. Long-term glycemic control is also important to reduce the risk of microvascular complications (neuropathy, retinopathy, and nephropathy) and perhaps macrovascular complications (stroke, coronary artery disease, and peripheral vascular disease). However, preventing hyperglycemia comes with the risk of inducing frequent or severe hypoglycemia, which can lead to lower quality of life, hospitalization, coma, and death.

Much of the challenge in maintaining euglycemia in patients with diabetes lies in the difficulty in matching carbohydrate intake with insulin administration, owing to errors in estimating the carbohydrate content in meals, variable insulin absorption, timing of insulin administration, and gastroparesis. Given these complicating factors, it is plausible that low carbohydrate intake and resulting lower prandial insulin bolus requirements may lead to better glycemic control, less blood glucose variability, and improved quality of life. ${ }^{24}$

\section{EFFICACY AND SAFETY}

Before the adoption of insulin as the gold standard treatment for type 1 diabetes, diet was one of the few therapy options available. In the early 20th century, the use of a very low-calorie, low-carbohydrate diet was used experimentally to manage it. ${ }^{9}$

The existing literature regarding the use of the ketogenic diet in type 1 diabetes is limited and has yielded mixed results. Many of the publications are case reports, and the majority are from the pediatric population for the treatment of medication-refractory epilepsy. The few studies are mostly observational and 
vary considerably in terms of the dietary macronutrient composition, making it difficult to generalize their results. Data on long-term cardiometabolic effects are also limited.

\section{Diet lowers blood glucose, sometimes dangerously}

Leow et $\mathrm{a}^{25}$ investigated the effects of a ketogenic diet $(<55 \mathrm{~g}$ of carbohydrates per day and fasting beta-hydroxybutyrate $\geq 0.4 \mathrm{mmol} / \mathrm{L}$ ) in 11 adults with type 1 diabetes who self-initiated the diet before study recruitment. Mean $\mathrm{HbA1c}$ of study participants was excellent at $5.3 \%$, and participants spent an impressive average of $74 \%$ of time within target range. However, many had a disproportionately high frequency and duration of hypoglycemic episodes.

Lennerz et $\mathrm{al}^{26}$ evaluated the effect of a very low carbohydrate diet on 316 patients with type 1 diabetes, using an online survey of a social media group. Average carbohydrate intake was $36 \pm 15 \mathrm{~g}$ of carbohydrates per day for an average duration of $2.2 \pm 2.9$ years. $\mathrm{Pa}$ tients achieved good glucose control (average HbA1c $5.7 \% \pm 0.66 \%$, average blood glucose by CGM $104 \pm 16 \mathrm{mg} / \mathrm{dL}$ ) and reported high satisfaction. The rate of severe adverse events was low and included 7 patients (2\%) with diabetes-related hospitalizations and 4 (1\%) with DKA.

In their small, randomized crossover study, Ranjan et $\mathrm{al}^{15}$ compared 1 week each on a low-carbohydrate diet $(\leq 50 \mathrm{~g}$ carbohydrates per day) and a high-carbohydrate diet $(\geq 250 \mathrm{~g}$ carbohydrates per day) in patients with type 1 diabetes using insulin pump therapy. The lowcarbohydrate diet group had significantly lower average daily blood glucose levels (122 mg/ $\mathrm{dL}$ vs $140 \mathrm{mg} / \mathrm{dL}, P=.02$ ), longer time in euglycemia (defined as 3.9-10.0 mmol/L [70-180 $\mathrm{mg} / \mathrm{dL}] ; 83 \%$ vs $72 \%, P=.004)$, less glycemic variability ( 1.9 vs $2.6 \mathrm{mmol} / \mathrm{L}, P=.02)$, lower total daily insulin dose ( 22 vs 39 units, $P=$ $.0001)$, and fewer daily units of bolus insulin administered (6.6 vs $23, P=.0001) .{ }^{15}$

\section{Weight loss possible but not well studied}

Another potential benefit of the ketogenic diet is weight loss. Obesity in patients with type 1 diabetes is a common problem that has worsened in recent decades. This may be in part due to the use of long-term insulin, an anabolic hormone that promotes weight gain. Obesity in type 1 diabetes can lead to metabolic syndrome and insulin resistance, as well as increased risk for microvascular complications. ${ }^{27-30}$

The ketogenic diet has been suggested as a tool for weight loss in overweight or obese patients with type 1 diabetes, although it has not been well studied in this population. In a well-designed crossover study, Rosenfalck et $\mathrm{al}^{31}$ looked at insulin sensitivity and BMI and found no significant change in weight or BMI after 3 months of a ketogenic diet in $10 \mathrm{pa}$ tients with type 1 diabetes.

\section{Animal studies have mixed results}

A few animal studies have examined the effect of a ketogenic diet in type 1 diabetes, but their significance in humans is unclear. Poplawski et $\mathrm{al}^{32}$ examined the effects of an 8 -week ketogenic diet (5\% carbohydrate, $8 \%$ protein, $87 \%$ fat) vs a high carbohydrate diet (64\% carbohydrate, $23 \%$ protein, $11 \%$ fat) in rat models of type 1 diabetes with nephropathy. The ketogenic diet group had a drastically improved albumin-creatinine ratio, indicating reversal of diabetic nephropathy.

Al-Khalifa et $\mathrm{al}^{33}$ placed 42 rats on either a normal diet, low carbohydrate diet, or high carbohydrate diet, all ad libitum, for 8 weeks. Half of each group was injected with streptozotocin to induce diabetes. Blood glucose levels and food and water intake increased with the normal and high-carbohydrate diets but not in the low-carbohydrate group $(P<.01)$. Weight gain was also significantly lower in the low-carbohydrate group $(P<.05)$. In the lowcarbohydrate group, the number of beta cells did not differ between the control group and the group with the streptozotocin injection, while the other diet groups had a significant decrease in beta-cell mass in the streptozotocin groups vs controls. These results suggest that a low-carbohydrate diet may attenuate or prevent the development of diabetes.

However, other rodent studies suggest potential harm. Kanikarla-Marie and Jain ${ }^{34}$ found that hyperketonemia in type 1 diabetes rat models induced macrophage-mediated damage and oxidative stress on hepatocytes, suggesting that a high ketone state may lead to liver damage. Grandl et $\mathrm{al}^{35}$ reported that 
mice fed a low-carbohydrate, high-fat ketogenic diet had a decrease in glucose tolerance due to blunted insulin-dependent hepatic glucose production during the fasting state.

\section{Effects on lipids mixed}

Concerns have been raised regarding the ketogenic diet and adverse lipid profile changes, but the literature is inconsistent, and few publications have assessed the issue specifically in type 1 diabetes. Effects of ketogenic diets such as decreased total cholesterol, low-density lipoprotein cholesterol, and triglyceride levels and increased high-density lipoprotein cholesterol levels have been reported. ${ }^{36-40}$

Yancy et $\mathrm{al}^{41}$ compared a low-carbohydrate diet to a low-fat diet in a randomized control trial of 120 overweight patients with hyperlipidemia. The low-carbohydrate diet led to greater decreases in serum triglyceride levels compared with patients on a low-fat $\operatorname{diet}(-74.2$ vs $-27.9 \mathrm{mg} / \mathrm{dL}, P=.004)$ and greater increases in high-density lipoprotein levels ( 5.5 vs $-1.6 \mathrm{mg} / \mathrm{dL}, P<.001$ ), but no significant differences were seen in low-density lipoprotein levels $(P=.2)$.

Using an online survey of a social media

Patients should be educated regarding symptoms of diabetic ketoacidosis group for children and adults with type 1 diabetes who were following a very low carbohydrate diet, Lennerz et $\mathrm{al}^{26}$ found that 51 of 316 respondents (16.1\%) reported having a diagnosis of dyslipidemia (triglyceride level $>130 \mathrm{mg} / \mathrm{dL}$, low-density lipoprotein level > $130 \mathrm{mg} / \mathrm{dL}$, or high-density lipoprotein level < $35 \mathrm{mg} / \mathrm{dL})$.

In a retrospective chart review of $30 \mathrm{pa}$ tients with either type 1 or type 2 diabetes on a low-carbohydrate diet ( $<30 \mathrm{~g}$ daily), O'Neill ${ }^{40}$ reported that low-density lipoprotein levels decreased by $17 \%$, from 155 to $130 \mathrm{mg} / \mathrm{dL}$ ( $P$ $=.004)$, and triglyceride levels decreased by 31\%, from 107 to $74 \mathrm{mg} / \mathrm{dL}(P<.05)$.

\section{Cardiac effects uncertain}

Although multiple studies have examined the effect of a ketogenic diet on clinical markers of cardiovascular risk (eg, BMI, blood pressure, lipids), the literature is limited and inconclusive regarding direct impacts on cardiac health. A ketogenic diet is known to cause electrolyte disturbances, increasing the risk of cardiac arrhythmias, and some studies have suggested that it may increase risk for a prolonged QT interval, atrial fibrillation, and other arrhythmias. ${ }^{42}$ A case series reported the de novo development of a long QT interval in 3 of 20 children following a ketogenic diet for seizure disorder. ${ }^{43}$ Long-term data of cardiac risk in the adult population are lacking.

\section{Blood pressure evidence scant}

Data regarding the impact of a ketogenic diet on blood pressure have been inconsistent, and little exists specifically in the setting of type 1 diabetes. Several studies demonstrated no significant reduction in blood pressure with a ketogenic diet, while others suggested a mild benefit. ${ }^{37,44-46}$ A long-term study on the cardiovascular impact of a ketogenic diet on 10 children with glut-1 deficiency over the course of 10 years found no change in systolic or diastolic blood pressures compared with healthy controls $(P=.11$ and $P=.37$, respectively $){ }^{36}$

\section{Possible microvascular benefit}

Very little research has been conducted on the impact of a ketogenic diet on microvascular complications in patients with diabetes. Studies on rats have found that a ketogenic diet improved or reversed diabetic nephropathy ${ }^{32}$ and reduced reactive oxygen species in peripheral nerve mitochondria, suggesting a positive impact on peripheral neuropathy. ${ }^{47}$

\section{SAFETY IN PEDIATRIC PATIENTS}

There is a lack of observational and prospective studies in children following a ketogenic diet, but several case reports have discussed its benefits in children with type 1 diabetes. ${ }^{2,3,48-52}$ They have found reductions in glycemia and glycemic variability and improvements in HbA1c level, growth rate, and lipid profiles, and many have been without severe adverse effects, like DKA and hypoglycemia.

Henwood et $\mathrm{al}^{48}$ described a 4 -year-old girl with pyruvate dehydrogenase deficiency, seizure disorder, and type 1 diabetes who was treated with a ketogenic diet. During 28 months follow-up, she had improved activity, better glycemic control, significant developmental advances, and an increase in linear growth from less than 5 th percentile to 50th percentile. However, the diet was discontinued when she developed severe DKA. 
Other case reports have revealed concerns about the diet's safety in children with and without diabetes. de Bock et $\mathrm{al}^{38}$ described 6 children with type 1 diabetes who were treated with carbohydrate-restrictive diets for epilepsy (diets varied from 20-90 grams per day in some, with others using a percentagebased formula ranging from $6 \%$ to $40 \%$ of the total daily calorie intake). Some children experienced weight loss and growth delay. Commonly observed effects were fatigue, reduced enjoyment in physical sports, and eating disorders. Ultimately, most families opted to return to a more liberal carbohydrate-containing diet.

Other reported long-term adverse effects are hyperlipidemia, kidney stones, vitamin and mineral deficiencies, electrolyte abnormalities, hypertriglyceridemia, gallstones, and elevated liver function tests. ${ }^{53,54}$ Short-term risks, including hypoglycemia, DKA, dehydration, anorexia, gastroesophageal reflux disease, vomiting, diarrhea, and abdominal pain have also been reported. However, many of the complications seen in children have not been well described in adults.

\section{CASE CONCLUSION}

Two years after starting the ketogenic diet, the patient reported that his blood glucose control remained significantly improved. His $\mathrm{HbA1c}$ level has remained in the desired range for the past 2 years; most recently it was $5.5 \%$. He lost 35 lbs with BMI improved from 30.4 to $25.5 \mathrm{~kg} / \mathrm{m}^{2}$. His total average daily basal insulin requirement decreased from 48 to 30 units per day, and he reported that he rarely requires prandial or correctional insulin boluses (before the diet, he averaged 33 units per day). According to his pump and CGM download, his bolus insulin requirements comprised only $3 \%$ of his total daily insulin dose (average of 1 unit per day). His blood glucose level remained within the goal range (3.9-10.0 mmol/L [70-180 mg/dL]) $98 \%$ of the time. He reported episodes of hypoglycemia 2 to 3 times every 2 weeks, but these have been mild and easily manageable. He has not had any episodes of DKA or severe hypoglycemia since starting the diet, but also admitted he would not feel safe following the diet without the safety afforded by CGM. He experienced an increase in low-density lipoprotein level up to $221 \mathrm{mg} / \mathrm{dL}$, requiring starting high-dose atorvastatin, which may be due to a high proportion of saturated animal fats in his diet. He responded well to statin therapy and his low-density lipoprotein level decreased to $104 \mathrm{mg} / \mathrm{dL}$, which has been maintained on the therapy.

\section{THE BOTTOM LINE}

Further research is needed on the efficacy and safety of the ketogenic diet in patients with type 1 diabetes. The diet may be appropriate for select patients, but only after a thorough discussion between patient and care team about the risks and benefits. A registered dietitian and specialists in diabetes care, education, endocrinology, and pharmacy should be part of any discussion. For patients on the diet, extra monitoring is critical, preferably with a CGM.

\section{DISCLOSURES}

The authors report no relevant financial relationships which, in the context of their contributions, could be perceived as a potential conflict of interest.

\section{A continuous glucose monitor can be useful for reducing hypoglycemia}

\section{REFERENCES}

1. Yancy WS Jr, Foy M, Chalecki AM, Vernon MC, Westman EC. A lowcarbohydrate, ketogenic diet to treat type 2 diabetes. Nutr Metab 2005; 2:34. doi: 10.1186/1743-7075-2-34

2. Dashti HM, Al-Zaid NS, Mathew TC, et al. Long term effects of ketogenic diet in obese subjects with high cholesterol level. Mol Cell Biochem 2006; 286(1-2):1-9. doi:10.1007/s11010-005-9001-x

3. Sharman MJ, Kraemer WJ, Love DM, et al. A ketogenic diet favorably affects serum biomarkers for cardiovascular disease in normalweight men. J Nutr 2002; 132(7):1879-1885. doi: 10.1093/jn/132.7.1879

4. Carmen M, Safer DL, Saslow LR, et al. Treating binge eating and food addiction symptoms with low-carbohydrate Ketogenic diets: a case series. J Eat Disord 2020; 8:2. doi:10.1186/s40337-020-0278-7

5. Sabounchi NS, Rahmandad H, Ammerman A. Best-fitting prediction equations for basal metabolic rate: informing obesity interventions in diverse populations. Int J Obes 2013; 37(10):1364-1370. doi: 10.1038/ijo.2012.218

6. Feinman RD, Pogozelski WK, Astrup A, et al. Dietary carbohydrate restriction as the first approach in diabetes management: critical review and evidence base. Nutrition 2015; 31(1):1-13. doi: 10.1016/j.nut.2014.06.011

7. Zinn C, Rush A, Johnson R. Assessing the nutrient intake of a lowcarbohydrate, high-fat (LCHF) diet: a hypothetical case study design. BMJ Open 2018; 8(2):e018846. doi:10.1136/bmjopen-2017-018846.

8. Masino SA, Rho JM. Mechanisms of ketogenic diet action. In: Noebels JL, Avoli M, Rogawski MA, Olsen RW, Delgado-Escueta AV, eds. Jasper's Basic Mechanisms of the Epilepsies. 4th ed. Bethesda, MD: National Center for Biotechnology Information (US); 2012.

9. Joslin EP. The treatment of diabetes mellitus. Can Med Assoc J 1916; 


\section{KETOGENIC DIETS}

6(8):673-684

10. Ciaraldi TP, Henry RR. Insulin regulation of ketone body metabolism. Wiley Online Library 2004. https://doi.org/10.1002/0470862092.d0308 Accessed July 15, 2021

11. Qiao Y, Gao Z, Liu Y, et al. Breath ketone testing: a new biomarker for diagnosis and therapeutic monitoring of diabetic ketosis. Biomed Res Int 2014; 2014:869186. doi:10.1155/2014/869186

12. Volek JS, Phinney SD. The Art and Science of Low Carbohydrate Performance. London, UK: Beyond Obesity LLC; 2012.

13. Bolinder J, Antuna R, Geelhoed-Duijvestijn P, Kröger J, Weitgasser R. Novel glucose-sensing technology and hypoglycaemia in type 1 diabetes: a multicentre, non-masked, randomised controlled trial. Lancet 2016; 388(10057):2254-2263. doi:10.1016/s0140-6736(16)31535-5

14. Hermanns N, Schumann B, Kulzer B, Haak T. The impact of continuous glucose monitoring on low interstitial glucose values and low blood glucose values assessed by point-of-care blood glucose meters: results of a crossover trial. J Diabetes Sci Technol 2014; 8(3):516-522. doi:10.1177/1932296814524105

15. Ranjan A, Schmidt S, Damm-Frydenberg C, Holst JJ, Madsbad S, Norgaard K. Short-term effects of a low carbohydrate diet on glycaemic variables and cardiovascular risk markers in patients with type 1 diabetes: A randomized open-label crossover trial. Diabetes Obes Metab 2017; 19(10);1479-1484. DOI: 10.1111/dom.12953

16. Saslow LR, Daubenmier JJ, Moskowitz JT, et al. Twelve-month outcomes of a randomized trial of a moderate-carbohydrate versus very low-carbohydrate diet in overweight adults with type 2 diabetes mellitus or prediabetes. Nutr Diabetes 2017; 7(12):304. doi:10.1038/s41387-017-0006-9

17. Westman EC, Yancy WS Jr, Mavropoulos JC, Marquart M, McDuffie JR. The effect of a low-carbohydrate, ketogenic diet versus a lowglycemic index diet on glycemic control in type 2 diabetes mellitus. Nut Metab (Lond) 2008; 5:36. doi:10.1186/1743-7075-5-36

18. Society of Metabolic Health Practitioners. Clinical guidelines for therapeutic carbohydrate restriction. Vers 1.3.8. Sep 25, 2020. https://www.lowcarbusa.org/standard-of-care/clinical-guidelines/ Accessed July 15, 2021.

19. Taylor SI, Blau JE, Rother KI. SGLT2 Inhibitors may predispose to ketoacidosis. J Clin Endocrinol Metab 2015; 100(8):2849-2852. doi:10.1210/jc.2015-1884

20. Handelsman Y, Henry RR, Bloomgarden ZT, et al. American Association of Clinical Endocrinologists and American College of Endocrinology Position Statement on the association of SGLT-2 inhibitors and diabetic ketoacidosis. Endocr Pract 2016; 22(6):753-762. doi:10.4158/ep161292.Ps

21. Ahrén B, Hirsch IB, Pieber TR, et al; ADJUNCT TWO Investigators. Efficacy and safety of liraglutide added to capped insulin treatment in subjects with type 1 diabetes: the ADJUNCT TWO randomized trial. Diabetes Care 2016; 39(10):1693-1701. doi:10.2337/dc16-0690

22. Mathieu C, Zinman B, Hemmingsson JU, et al; ADJUNCT ONE Investigators. Efficacy and safety of liraglutide added to insulin treatment in type 1 diabetes: the ADJUNCT ONE Treat-To-Target randomized trial. Diabetes Care 2016; 39(10):1702-1710. doi:10.2337/dc16-0691

23. Moriconi E, Camajani E, Fabbri A, Lenzi A, Caprio M. Very-low-calorie ketogenic diet as a safe and valuable tool for long-term glycemic management in patients with obesity and type 2 diabetes. Nutrients 2021; 13(3):758. doi:10.3390/nu13030758

24. Braffett BH, Dagogo-Jack S, Bebu I, et al; DCCT/EDIC Research Group. Association of insulin dose, cardiometabolic risk factors, and cardiovascular disease in type 1 diabetes during 30 years of followup in the DCCT/EDIC study. Diabetes Care 2019; 42(4):657-664. doi:10.2337/dc18-1574

25. Leow ZZX, Guelfi KJ, Davis EA, Jones TW, Fournier PA. The glycaemic benefits of a very-low-carbohydrate ketogenic diet in adults with type 1 diabetes mellitus may be opposed by increased hypoglycaemia risk and dyslipidaemia. Diabet Med 2018; 35:1258-1263. doi:10.1111/dme.13663

26. Lennerz BS, Barton A, Bernstein RK, et al. Management of type 1 diabetes with a very low-carbohydrate diet. Pediatrics 2018; 141(6) e20173349. doi:10.1542/peds.2017-3349

27. Corbin KD, Driscoll KA, Pratley RE, Smith SR, Maahs DM, MayerDavis EJ; Advancing Care for Type 1 Diabetes and Obesity Network (ACT1ON). Obesity in type 1 diabetes: pathophysiology, clinical impact, and mechanisms. Endocr Rev 2018; 39(5):629-663. doi:10.1210/er.2017-00191

28. Atkinson MA, Eisenbarth GS, Michels AW. Type 1 diabetes. Lancet 2014; 383(9911):69-82. doi:10.1016/s0140-6736(13)60591-7

29. Skelton JA, Irby MB, Grzywacz JG, Miller G. Etiologies of obesity in children: nature and nurture. Pediatr Clin North Am 2011; 58(6):1333-1354, ix. doi:10.1016/j.pcl.2011.09.006

30. Polsky S, Ellis SL. Obesity, insulin resistance, and type 1 diabetes mellitus. Curr Opin Endocrinol Diabetes Obes 2015; 22(4):277-282. doi:10.1097/med.0000000000000170

31. Rosenfalck AM, Almdal T, Viggers L, Madsbad S, Hilsted J. A low-fat diet improves peripheral insulin sensitivity in patients with type 1 diabetes. Diabet Med 2006; 23(4):384-392. doi:10.1111/j.1464-5491.2005.01810.x

32. Poplawski MM, Mastaitis JW, Isoda F, Grosjean F, Zheng F, Mobbs CV. Reversal of diabetic nephropathy by a ketogenic diet. PloS One 2011; 6(4):e18604. doi:10.1371/journal.pone.0018604

33. Al-Khalifa A, Mathew TC, Al-Zaid NS, Mathew E, Dashti H. Low carbohydrate ketogenic diet prevents the induction of diabetes using streptozotocin in rats. Exp Toxicol Pathol 2011; 63(7-8):663-669. doi:10.1016/j.etp.2010.05.008

34. Kanikarla-Marie P, Jain SK. Role of hyperketonemia in inducing oxidative stress and cellular damage in cultured hepatocytes and type 1 diabetic rat liver. Cell Physiol Biochem 2015; 37(6):2160-2170. doi:10.1159/000438573

35. Grandl G, Straub L, Rudigier C, et al. Short-term feeding of a ketogenic diet induces more severe hepatic insulin resistance than an obesogenic high-fat diet. J Physiol 2018; 596(19):4597-4609. doi:10.1113/jp275173

36. Heussinger N, Della Marina A, Beyerlein A, et al. 10 patients, 10 years - long term follow-up of cardiovascular risk factors in Glut1 deficiency treated with ketogenic diet therapies: a prospective, multicenter case series. Clin Nutr 2018; 37(6 pt A):2246-2251. doi:10.1016/j.clnu.2017.11.001

37. Kosinski C, Jornayvaz FR. Effects of ketogenic diets on cardiovascular risk factors: Evidence from animal and human studies. Nutrients 2017; 9(5):517. doi:10.3390/nu9050517

38. de Bock M, Lobley K, Anderson D, et al. Endocrine and metabolic consequences due to restrictive carbohydrate diets in children with type 1 diabetes: an illustrative case series. Pediatr Diabetes 2018; 19(1):129-137. doi:10.1111/pedi.12527

39. Krebs JD, Parry Strong A, Cresswell P, Reynolds AN, Hanna A, Haeusler S. A randomised trial of the feasibility of a low carbohydrate diet vs standard carbohydrate counting in adults with type 1 diabetes taking body weight into account. Asia Paci J Clin Nutr 2016; 25(1):78-84. doi:10.6133/apjcn.2016.25.1.11

40. O'Neill BJ. Effect of low-carbohydrate diets on cardiometabolic risk insulin resistance, and metabolic syndrome. Curr Opin Endocrinol Diabetes Obes 2020; 27(5):301-307. doi:10.1097/med.0000000000000569

41. Yancy WS Jr, Olsen MK, Guyton JR, Bakst RP, Westman EC. A lowcarbohydrate, ketogenic diet versus a low-fat diet to treat obesity and hyperlipidemia: a randomized, controlled trial. Ann Int Med 2004; 140(10):769-777. doi:10.7326/0003-4819-140-10-200405180-00006

42. Zhang $\mathbf{S}$, Zhuang $\mathbf{X}$, Lin $\mathbf{X}$, et al. Low-carbohydrate diets and risk of incident atrial fibrillation: a prospective cohort study. J Am Heart Assoc 2019; 8(9):e011955. doi:10.1161/jaha.119.011955

43. Best TH, Franz DN, Gilbert DL, Nelson DP, Epstein MR. Cardiac complications in pediatric patients on the ketogenic diet. Neurology 2000; 54(12):2328-2330. doi:10.1212/wnl.54.12.2328

44. Cicero AF, Benelli M, Brancaleoni M, Dainelli G, Merlini D, Negri R. Middle and long-term impact of a very low-carbohydrate ketogenic diet on cardiometabolic factors: a multi-center, cross-sectional, 


\section{BUEHLER AND COLLEAGUES}

clinical study. High Blood Press Cardiovasc Prev 2015; 22(4):389-394. doi:10.1007/s40292-015-0096-1

45. Foster GD, Wyatt HR, Hill JO, et al. A randomized trial of a low-carbohydrate diet for obesity. N Engl J Med 2003; 348(21):2082-2090. doi:10.1056/NEJMoa022207

46. Mayer SB, Jeffreys AS, Olsen MK, McDuffie JR, Feinglos MN, Yancy WS Jr. Two diets with different haemoglobin A1c and antiglycaemic medication effects despite similar weight loss in type 2 diabetes. Diabetes Obes Metab 2014; 16(1):90-93. doi:10.1111/dom.12191

47. Cooper MA, McCoin C, Pei D, Thyfault JP, Koestler D, Wright DE. Reduced mitochondrial reactive oxygen species production in peripheral nerves of mice fed a ketogenic diet. Exp Physiol 2018; 103(9):1206-1212. doi:10.1113/ep087083

48. Henwood MJ, Thornton PS, Preis CM, Chee C, Grimberg A. Reconciling diabetes management and the ketogenic diet in a child with pyruvate dehydrogenase deficiency. J Child Neurol 2006; 21(5):436-439. doi:10.1177/08830738060210051001

49. Kessler SK, Neal EG, Camfield CS, Kossoff EH. Dietary therapies for epilepsy: future research. Epilepsy Behav 2011; 22(1):17-22. doi:10.1016/j.yebeh.2011.02.018
50. Aylward NM, Shah N, Sellers EA. The ketogenic diet for the treatment of myoclonic astatic epilepsy in a child with type 1 diabetes mellitus. Can J Diabetes 2014; 38(4):223-224. doi:10.1016/j.jcjd.2014.05.002

51. McClean AM, Montorio L, McLaughlin D, McGovern S, Flanagan N. Can a ketogenic diet be safely used to improve glycaemic control in a child with type 1 diabetes? Arch Dis Child 2019; 104(5):501-504. doi:10.1136/archdischild-2018-314973

52. Aguirre Castaneda RL, Mack KJ, Lteif A. Successful treatment of type 1 diabetes and seizures with combined ketogenic diet and insulin. Pediatrics 2012; 129(2):e511-514. doi:10.1542/peds.2011-0741

53. Kanikarla-Marie $\mathbf{P}$, Jain SK. Hyperketonemia and ketosis increase the risk of complications in type 1 diabetes. Free Radical Biol Med 2016; 95:268-277. doi:10.1016/j.freeradbiomed.2016.03.020

54. Keene DL. A systematic review of the use of the ketogenic diet in childhood epilepsy. Pediatr Neurol 2006; 35(1):1-5. doi:10.1016/j.pediatrneurol.2006.01.005

Address: Kevin Pantalone, DO, ECNU, FACE, Endocrinology and Metabolism Institute, TWG3-4, Cleveland Clinic, 9500 Euclid Avenue, Cleveland, $\mathrm{OH}$ 44195; pentalk@gmail.com 